\title{
ANALYSIS OF TEACHER TALK IN ENGLISH CLASSES IN VOCATIONAL HIGH SCHOOL TELADAN MEDAN
}

\author{
Yuni Ansari Rambe \\ English Applied Linguistics Department, Postgraduate Program \\ State University of Medan, North Sumatera, Indonesia \\ Corresponding author: yz.ansari.rambe@gmail.com
}

\begin{abstract}
The objective of this study at describing the types of Teacher Talk, the effectiveness/ineffectiveness of Teacher Talk, and the aspect of Teacher Talk in classroom observation. This study used descriptive qualitative method is employed in this study which tries to describe all phenomena that occurred in the classroom This study involved an English teacher as research subject in his class. The subject of this study has implemented English talk as a means of communication in learning process of his classroom. The subject here is a female teacher who has been teaching English for one years and graduated from the university of Medan. This study was conducted in SMK Teladan located in Medan city. This study was done in twelfth grade. This class consists of 22 students with 11 are males and 11 are females. The main data was taken through observation technique. The data was collected by using recording and field notes. From analysis done, it was found that English teacher performed their interactional communicative features out of five in the classroom. The features are 1. Referential Questions 2. Content Feedback 3. Student initiated Talk. All communicative interactional features of teacher it happened in discussion activities, it could be concluded that the teacher performs their interactional communicative features in classroom interaction out of five. There features are: 1. Referential Questions 2. Content Feedback 3. Student initiated Talk.
\end{abstract}

Keywords: Teacher talk, type of teacher talks, classroom interaction

\section{Introduction}

The language used by the teacher or teacher talk has important role that influences the success of English learning process. Teacher talk is used to guide the learning activity of the students in constructing a joint and share the educational knowledge with the students and Communication also an outward extension of thought. It helps in the process of arranging thought, linking one idea to another. Communication includes both verbal (that is, language in written and spoken form) and non-verbal (that is, language in conventional symbols and ways of representation through drawing and diagrams) forms. 
One of the principal means through which patterns of interaction are constructed is language. To interpret the patterns of life, members need to process linguistic and non-verbal aspects of the social interactions of others. Language, in relationship to the social construction of life in classrooms, refers to the oral and written discourse norms, expectations, and strategies that members establish through their daily interactions. Defined in this way, the language-of the-classroom is a group of constructed phenomena, a negotiated system of meaning, and as et of conventions for interacting, participating and communicating information and knowledge within a particular classroom. Communication is called for when the language user recognizes a situation which requires the conveyance of information to establish a convergence of knowledge, so that this situation can be changed in some way. This transaction requires the negotiation of meaning through interaction. I refer to this negotiation as discourse (Widdowson, 1984: 100).

The use of language in any classroom is interesting from an educational point of view because education itself is conducted fundamentally through the medium of language. The term "the language classroom» is used here to refer to a classroom in which the primary concern is the development of a language that is not the first language of the learners. the teacher uses talk to do two things: (1) Elicit relevant knowledge from students, so that they can see what students already know and understand; (2) Respond to things that students say.

Teacher talk it is important to the teachers should realize how much they themselves talk, and what kind of talk should be performed. Cullen stated that while the question of how much teachers talk is still important, more emphasis is given to how effectively they are able to facilitate learning and promote communicative interaction in their classroom through. The interaction in a language classroom is very complicated. Many problems appeared to develop teaching learning process through a communicative interaction because students get a difficulty in expressing themselves in using English language which is not their mother tongue. Therefore, the ways of teacher both using language and giving the students opportunity in developing language are very important to understand. In other words, teacher talk which is aimed to establish and maintain good communicative practices in the complex series discourse, takes a great proportion in the classroom. "Creating a reallife situation in English language teaching" has become a fashion in recent years. To be exact, that is the communicative approach.

It provides a way to solve the problem that has existed in ELT for many years. The problem is that the students, after receiving several years of English teaching, are still unable to use the language, to communicate with the language. The communicative app roaches have suggested that one goal of English language teaching should be to promote genuine and natural classroom communication. Until comparatively recently, teacher talk in the EFL classroom was considered to be a problematic area for language teachers. For one time, it was thought that "good" teacher talk meant "little" teacher talk, since too much teacher talks deprived students of opportunities to speak. However, it should be the "quality" rather than the "quantity" that counts. "Good teacher talk" should be judged by how effectively it was able to facilitate 
learning and promote communicative interaction in the classroom. The teacher talk that promotes the facilitation of classroom interaction is therefore called communicative.

The teacher talk includes, for example, the kind of questions they ask, the speech, modifications they make when talking to learners, and the way they react to student's errors. Successful language learning depends on classroom communication, i.e. interaction learners engage in with their teacher and other learners. The discourse among students and the teacher and among students themselves is central for foreign language learning as it contextualizes learning experiences while active participation in classroom discourse engages learners in the learning process.

\section{Literature Review}

Classroom Interaction Ellis pointed out that it is useful to distinguish two different but related meanings of "interaction". First, interaction can be viewed as the social behavior that occurs when one person communicates with another. Interaction in this sense is interpersonal. It can occur face-to-face, in which case it usually takes place through the oral medium, or it can occur as displaced activity, in which case it generally involves the written medium. Second, interaction can occur inside our minds, both when we engage in the kind of private speech and more covertly, when different modules of the mind interact to construct an understanding of or a response to some phenomenon. Interaction in this kind is Intrapersonal. Classroom interaction plays important role in succeeding language learning process. All right as stated in Ellis sees interaction as the fundamental fact of classroom pedagogy because everything that happens in the classroom happens through a process of live person-to-person interaction. A more social view, Allwright et al. stated interaction with other language users as essential to acquisition and considers the quality of that social experience crucial to successful classroom language learning.

\section{Teacher Talk and Pedagogic Goal}

Sinclair as quoted by Yanfen and Yuqin gave definition of teacher talk is that the language in the classroom that takes up a major portion of class time employed to give directions, explain activities and check students" understanding. Teacher talk is the language that teacher convey to the students in order to organize the activities in the classroom and assist students in the process of acquisition. Teacher talk has its own specific features. It is different with talk outside the classroom. The teacher in the process of teaching and learning simplified and modified their talk more comprehensible thus student is easier in understanding the target language. According to Walsh contexts are locally constructed by participants through and in their interaction in the light of overall institutional goals and immediate pedagogic objective. In other words, pedagogy and interaction come together through talk. pedagogic goals are manifested in the talk-in-interaction. Using the term mode encompasses the interrelatedness of language use and teaching purpose. From this rationale, a framework Self-Evaluation of Teacher Talk (SETT) was proposed by Walsh 
in which using term mode, typical pedagogical goals together with interactional features.

\section{Interactional Features}

Interactional features refer to specific interactional features of classroom discourse that may help or hinder communication. Things like wait time, confirmation check, display question, etc. are examples of interactional features. In his study of teacher talk, Walsh found that certain interactional features facilitated learning opportunity, while others appeared to hinder opportunities for learning. That is, depending on a teacher's pedagogical goal, choice of language could either construct or obstruct learning opportunity.

In other words, teacher talk which is aimed to establish and maintain good communicative practices in the complex series discourse, takes a great proportion in the classroom. Therefore, through investigating interaction in classroom teachers will be able to develop their awareness of applying appropriate teacher talk in teaching.

There are five features Communicative Teacher Talk they are .1. Referential Questions 2. Content Feedback 3. Avoidance of the IRF Sequence 4. Student initiated Talk 5. The Teaching of Value Rather Than Significance

\section{Research Method}

This study used descriptive qualitative method is employed in this study which tries to describe all phenomena that occurred in the classroom This study involved an English teacher as research subject in his class. The subject of this study has implemented English talk as a means of communication in learning process of his classroom. The subject here is a female teacher who has been teaching English for one years and graduated from the university of Medan. This study was conducted in SMK Teladan located in Medan city. This study was done in twelfth grade. This class consists of 22 students with 11 are males and 11 are females. The main data was taken through observation technique. The data was collected by using recording and field notes.

\section{Findings and Discussion}

From analysis done, it was found that English teacher performed their interactional communicative features out of five in the classroom. The features are .1. Referential Questions 2. Content Feedback 3. Student initiated Talk. All communicative interactional features of teacher it happened in discussion activities.

1. Referential questions are genuine questions for which the teacher does not know the answers and therefore has a genuine communicative purpose. This is in contrast to displaying their understanding of knowledge. There is plenty of evidence to suggest that in the nowadays classrooms, the vast majority of questions teachers ask are display questions without communicative purposes. While in real life, most questions are referential. There is a marked difference between typical classroom talk and nonclassroom talk in this respect.

Transcript A:

T: Today, we are going to study Lesson Six "The Human Touch". First, I will give you several minutes to go through the text, and after that, I have several questions for you ... ok now? 
S: Yes.

T: Who is O' Henry?

S1: Of course, a writer.

T: Good. Who knows more about the writer?

S2: A famous writer.

$\mathrm{T}$ : Right. Who knows why he is known as a famous writer?

S3: Sorry.

T: Don't worry. Think it over.

S4: He is a famous short story author.

T: Fine. What else do you know about him?

S4: Sorry.

T: Ok. Now, let's study the new words in this text. The first one is

"victim". "Victim" means person, animal, etc.

suffering death, injury or loss. Can you make a sentence with "victim"?

S5: Sorry, I can't do it.

T: Ok.

We view the class as a failure for it is a typical uncommunicative fragment of classroom talk. The class was thought of as uncommunicative simply because it fails to exhibit features of communication which is in contexts outside the classroom. Our questions are all display questions, since the purpose is to know if the students understand the text and the words, and to enable them to display their knowledge. Our feedback to the students' responses is simply acknowledgements to mean that the answer is acceptable. The talk obviously follows the IRF sequence. That is, the teacher asks a question, then the student responds, and the teacher asks another. Soon, we find that the students easily get bored, and gradually they become more and more uncooperative. They begin to talk to each other, flip through the book or even fall asleep in the class. We know that it is not the students that are to blame, but the teaching, the method. Then we experimented with a new approach to classroom questioning and initiation as is rep resented by Transcript $B$.

\section{Content Feedback}

Feedback on content involves responding to the content of what learners are saying, rather than commenting solely on the form. After all, if no attention is paid to the meanings the learner is expressing, there is no point in asking referential questions.

Transcript B:

$\mathrm{T}$ : Hi, Dessy, do you like reading novels?

S1: Yes, of course. I read a lot in my spare time.

$\mathrm{T}$ : Ha, the same with me. Then, which novel do you like best?

S1: Oh, "Gone with the Wind" is my favorite book, and I have ever read "A farewell to Arms". I could say it is perfect.

$\mathrm{T}$ : I have read it for several times, to tell you the truth. And I find the "Gone with the Wind" is very attractive indeed.

Now, here comes the question, have you read the "The Gif $t$ of the Magi"?

S1: Oh, of course. The story is very impressive. 
Proceedings of the $1^{\text {st }}$ Annual International Conference on Language and Literature, 18-19 April 2018, Fakultas Sastra, UISU, Medan, Indonesia.

\section{T: But I wonder who wrote it?}

S2: O' Andy.

T: Great. Who can tell me what novels he had written besides this one?

S3: The Cop and the Anthem.

T: Good, Lesson Six tells us a story written by the same author. Now let us look at what happened to the girl named Adwerd and why Sue called the painted leaf Behrman's masterpiece. Read the text and tell me the answers.

(Several minutes later)

S4: Sue's roommate Adwerd caught pneumonia, and she decided that she would die when the lastivy leaf fell.

T: Good. . . Now let us relax a little. Harmy, do you like drawing?

S5: Yes, I began to draw when I was a little boy.

$\mathrm{T}$ : Oh. How do you tell the genuine from the fake ones?

S5: Ha. . . I. . I. . . perhaps, I think it is not an easy job for me if the fake is too much like the real one. T: Now, let's come to the second question.

S6: Because it was so perfect that the girls both mistook it for the real thing.

We chose Transcript B not because we think it is flawless but because we feel it is an example of genuine interaction between ourselves and the students, and in particular because WE consider it a breakthrough with the class. In the past, students were reluctant in initiating discussions, asking or answering questions during the class probably because the questions were not communicative and they were not sure about their language ability. During the class, insecurities were somewhat forgotten as the students forgot about the classroom context and enthusiastically attempted to answer the questions they are interested in. More real communication was seen when they began to differ in their opinions. In the class talk, most of the questions were referential with the communicative purpose and the teacher's response was on the content rather than on the form.

\section{Student initiated Talk}

Acquisition is facilitated by the negotiation of meaning in interaction. Teachers should try to negotiate meaning with students, through asking for clarification and repetition, and giving students opportunities to interrupt the teachers. Although there is usually much less learner initiated than teacher-initiated content in classroom, it is usually from the former that learners claim to have learned the most. Some teachers give the students absolutely no space meaningful negotiations. They are complete authority ignoring the students' contribution, in fear that the teaching objectives will not be met. There is no interaction between students. They only allow time for this, if any, in the free practice towards the end of the lesson, and thus the lesson not at all flowing along the interactive path. Usually the teacher does all the talking, and then the students are left on their own. Then, how should the teacher react if the students ask questions? Does the teacher simply provide the answer or guide the students to solve the problem by themselves? It is easy, in any problem-solving situation, for the wrong 
person to become responsible for solving the learning problems. Obviously, providing the answers promptly deprives the learner of opportunities to learn how to solve problems and snuff the communication between the teacher and the learner. So, the key question is often not how to solve the problem itself, but how to make sure that the right person solves it. The teacher should always ensure that she herself and the learners play their proper roles in problem solving processes.

Transcript $\mathrm{C}$

S: Excuse me, I don't understand this word.

$\mathrm{T}$ : Hm, delegate. So the meaning has to be found. Do you remember seeing it before anywhere?

S: Ah, yes, now I remember. I think it was in the last unit. (flipping through the pages) Here it is. It means to get

someone else to do something that you normally do yourself.

$\mathrm{T}$ : Yes, can you think of an example?

$\mathrm{S}$ : Yes, like when you ask one of us to clean the blackboard or give out the books. Then you delegate those jobs to us,

right?

T: Good.

\section{Conclusions}

From explanation above, it could be concluded the result of this study can stimulate the other researchers who are interested in topic and give contribution as references in the in - depth study of Analysis of teacher talk in english classess for further researchers.

Hopefully, the finding of this research can help to give fositive contribution in improving teacher talk in english, they will be highly motivated and consequenty more successful in acquiring the target languaguage. Then, they can improve their speaking skill in daily life.

\section{References}

All wright, Dick, and Hanks, Judith. The Developing Language Learner: An Introduction to Exploratory Practice. New York: Palgrave Macmillan, 2009.

Brown, H. Douglas. Teaching by Principles; An interactive Approach to Language Pedagogy. New York: Person Education, 2001

Brumfit, C. J. \& Johnson, K. (1983). The Communicative Approach to Language Teaching. Oxford: Oxford University Press.

Cullen, R. (1998). Teacher Talk and the Classroom Context. ELT Journal, (52 /1): 1792186.

Ellis, Rod. The Study of Second Language Acquisition (Oxford Applied Linguistics). New York: Oxford University Press, 1994. 